\title{
Exploring Bovine Pancreatic Trypsin Inhibitor Phase Transitions
}

\author{
Sylvain Grouazel, ${ }^{\dagger}$ Françoise Bonneté, ${ }^{\dagger}$ Jean-Pierre Astier, ${ }^{\dagger}$ Natalie Ferté, ${ }^{\dagger}$ Javier Perez, ${ }^{\ddagger}$ and \\ Stéphane Veesler*,† \\ Centre de Recherche en Matière Condensée et Nanosciences, CRMCN-CNRS, Campus de Luminy, Case 913, \\ F-13288 Marseille Cedex 09, France, and Synchrotron SOLEIL, L'Orme des Merisiers BP 48 Saint-Aubin, \\ F-91192 Gif sur Yvette Cedex, France
}

Received: May 3, 2006; In Final Form: August 7, 2006

\begin{abstract}
This paper presents an investigation of the phase diagram of BPTI (bovine pancreatic trypsin inhibitor)/350 $\mathrm{mM} \mathrm{KSCN}$ at $\mathrm{pH} 4.9$ by direct observation and numerical simulations. We report optical microscopy and light and X-ray scattering experiments coupled with theoretical data analysis using numerical tools. The phase diagram is thoroughly determined, as a function of temperature. Two polymorphs are observed by video microscopy and their solubility measured. In this phase diagram, the liquid-liquid phase separation (LLPS) is metastable with respect to the solid-liquid phase separation. Above the $T_{\mathrm{L}-\mathrm{L}}$ boundary curve, solutions are composed of a mixture of BPTI monomers and decamers. Attractive interactions are stronger between decamers than between monomers. Below the $T_{\mathrm{L}-\mathrm{L}}$ boundary curve, the dense phase is highly concentrated in protein and composed of BPTI decamers alone. Thus, the driving force for liquid-liquid or liquid-solid phase separation is the attraction between decamers at low $\mathrm{pH}$. The structure factors of the dense phases are characteristic of repulsive dense phases because of a hard sphere repulsion core, meaning that in the dense phase proteins are actually in contact (interparticle distance of $53 \AA$ ). In agreement with the Oswald rule of stages, LLPS occurs prior to and impedes the solid nucleation.
\end{abstract}

\section{Introduction}

A deep understanding of the phase diagrams of colloidal or biological molecules is of considerable importance in industrial science, for example, for paints, foods, or pharmaceuticals ${ }^{1,2}$ and in structural genomics and drug design for the success of crystallization experiments. ${ }^{3}$ Protein phase separations can also be the cause of human diseases, such as cataract ${ }^{4}$ or sickle cell disease. ${ }^{5}$

Despite their fundamental importance, phase diagrams of only a few proteins have been studied: insulin, ${ }^{6}$ fibrinogen, ${ }^{7} \gamma$-crystallin, ${ }^{8}$ lysozyme, ${ }^{4,9-12}$ concanavalin, ${ }^{13}$ canavalin, ${ }^{14} \alpha$-amylase, ${ }^{15,16}$ collagenase, ${ }^{17}$ bovine pancreatic trypsin inhibitor (BPTI), ${ }^{16,18}$ apoferritin, ${ }^{19}$ endoglucanase $\mathrm{A},{ }^{20}$ and the photochemical reaction center from Rhodobacter sphaeroides $\mathrm{Y}^{21}$

Recently, there has been a renewed enthusiasm for phasetransition studies of colloids ${ }^{22}$ and proteins ${ }^{22-27}$ due to advances in experimental and computational technologies. Moreover, colloids and proteins can be used as "model" (model means available in sufficient quantity for many fundamental studies and not representative of all other biological molecules) systems for studying nucleation and crystal growth mechanisms in solution, since their nanosizes, shapes, and interactions enable them to be studied by scattering techniques, such as light scattering or small angle X-ray scattering (SAXS), ${ }^{22,28,29}$ and to be observed during crystallization by in situ atomic force microscopy. ${ }^{30-32}$

In this paper we thoroughly characterize the phase diagram of BPTI in $350 \mathrm{mM} \mathrm{KSCN}$, pH 4.9, as a function of temperature

\footnotetext{
* Corresponding author. Tel: 336-62-922866. Fax: 334-91-418916 E-mail: veesler@crmcn.univ-mrs.fr.

CRMCN-CNRS.

$\doteqdot$ Synchrotron SOLEIL.
}

and report SAXS investigations of its liquid-liquid phase separation (LLPS) with the aim of explaining and understanding solid-phase nucleation in the vicinity of a LLPS. We demonstrate that interactions and oligomerization need to be taken together in order to explain the liquid and solid nucleation behavior of BPTI.

\section{Results and Discussions}

2.1. Phase Diagram. 2.1.1. Solubility. Figure 1 shows the BPTI crystal habits of the two polymorphic modifications that we observed by video microscopy at $\mathrm{pH} 4.9$ from $350 \mathrm{mM}$ KSCN solution. The bipyramid habit (Figure 1a) has the appearance of the chloride hexagonal polymorph, ${ }^{33}$ while the platelet habit (Figure 1b) is the thiocyanate monoclinic polymorph. ${ }^{34}$ To our knowledge, this is the first time that the chloride-like hexagonal polymorph has been observed in KSCN. Moreover, this assumption is confirmed by the reverse solubility curve measured for the bipyramid polymorph (Figure 2a). This reverse temperature dependence has previously been observed for the chloride-like hexagonal polymorph in acidic conditions in $\mathrm{NaCl}^{18}$ and $\mathrm{NaBr}{ }^{35}$ Note that the monoclinic polymorph solubility has direct temperature dependence and solubility curves cross at $12{ }^{\circ} \mathrm{C}$.

2.1.2. Liquid-Liquid Phase Separation. Figure 2b shows the complete $T_{\mathrm{L}-\mathrm{L}}$ boundary curve. Due to protein solution instability with respect to crystal nucleation at $C>120 \mathrm{mg} / \mathrm{mL}$, it is impossible to measure directly the $T_{\mathrm{LL}}$ of these solutions. Therefore, the concentration of the dense phase or right branch of the liquid-liquid coexistence curve was measured by UV spectroscopy, as described in section 2.2. (Table 1). The accuracy of these points is very low because the dense phase gels and represents a volume fraction of less than $4 \%$ of the starting solution (Table 1). 

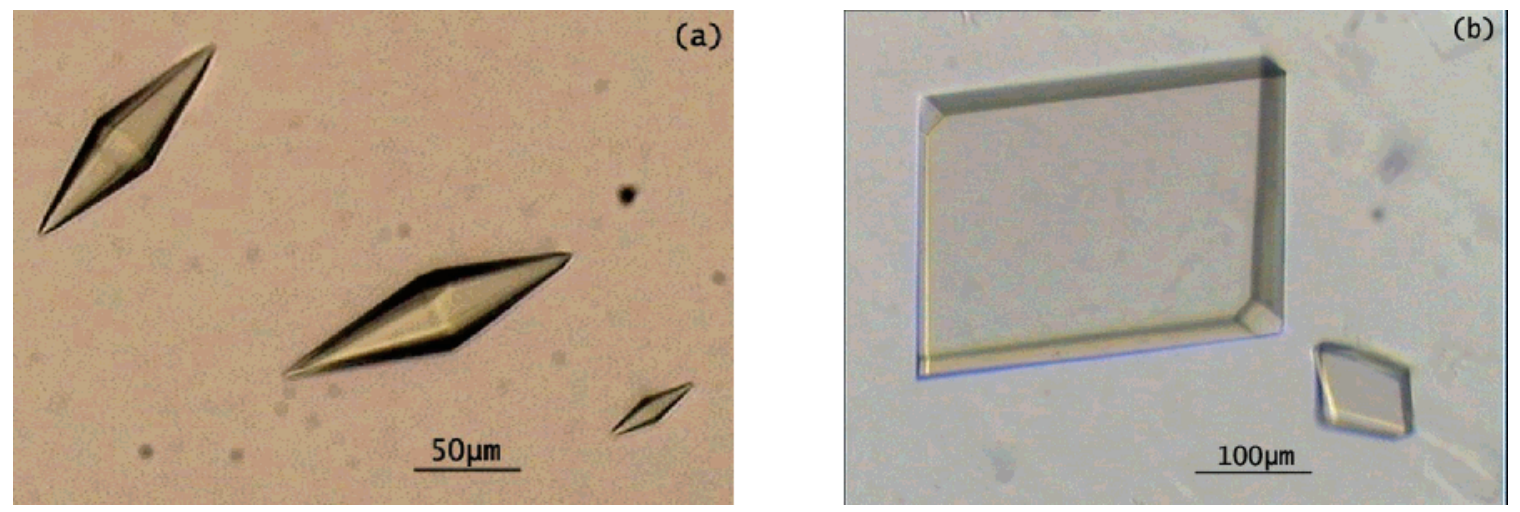

Figure 1. Crystal habits of BPTI crystals grown from $350 \mathrm{mM} \mathrm{KSCN}$ solution: (a) bipyramid and (b) monoclinic polymorphs.
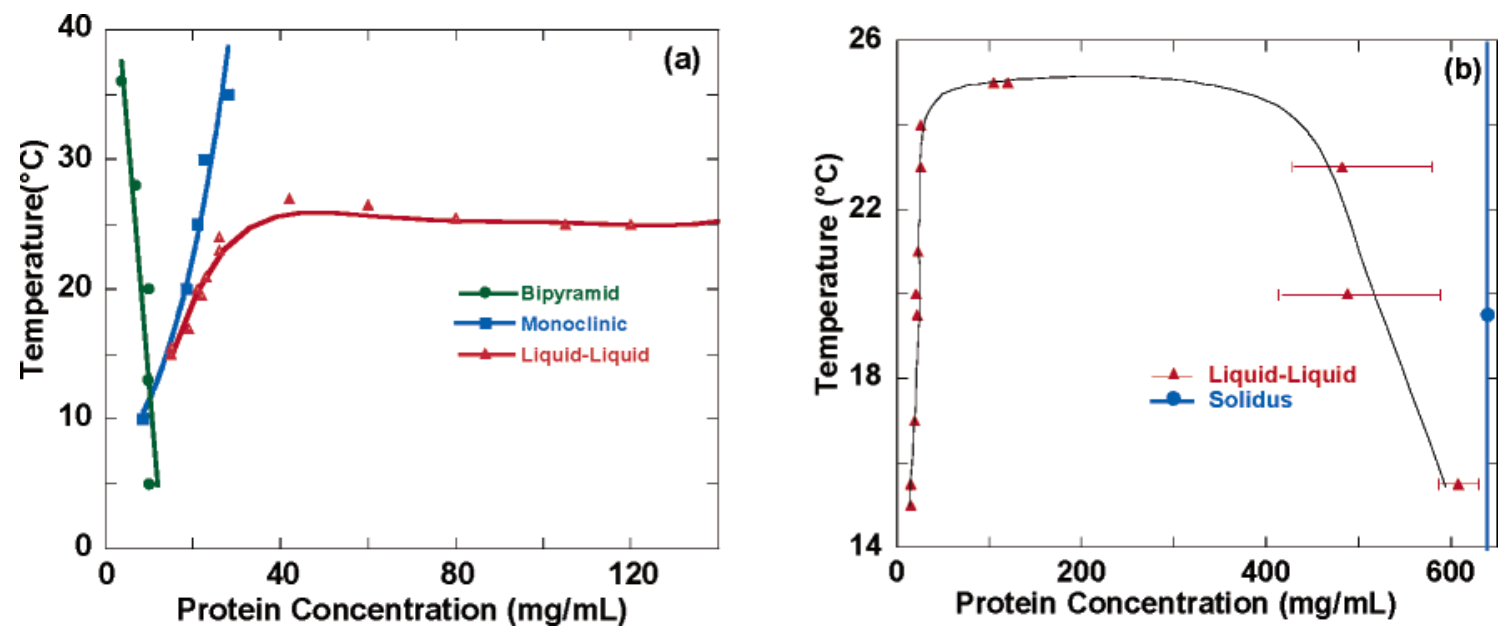

Figure 2. Phase diagram of BPTI measured at pH 4.9 in $350 \mathrm{mM} \mathrm{KSCN}$ : (a) in the concentration range $0-140 \mathrm{mg} / \mathrm{mL}$; the solubility curve of monoclinic BPTI are from Lafont et al. ${ }^{18}$ and the $T_{\mathrm{L}-\mathrm{L}}$ boundary curve from Grouazel et al. ${ }^{37}$ (b) The complete $T_{\mathrm{L}-\mathrm{L}}$ boundary curve (this study); error bars for $C<200 \mathrm{mg} / \mathrm{mL}$ have the size of the point on the graph and solid line is a guideline. The circle is a point of the solidus line.

TABLE 1: Characterization of the Two Phases Obtained after the LLPS

\begin{tabular}{ccccccc}
\hline \multirow{2}{*}{$\begin{array}{c}\text { total protein } \\
\text { concn }\end{array}$} & & & dense & \multicolumn{2}{c}{ volume \% } \\
\cline { 5 - 6 }$(\mathrm{mg} / \mathrm{mL})$ & $\left({ }^{\circ} \mathrm{C}\right)$ & $\begin{array}{c}\text { supernatant } \\
(\mathrm{mg} / \mathrm{mL})\end{array}$ & $\begin{array}{c}\text { denase } \\
\text { phg/mL) }\end{array}$ & supernatant & $\begin{array}{c}\text { dense } \\
\text { phase }\end{array}$ \\
\hline 40 & 23 & 26 & 482 & 96.3 & 3.7 \\
30 & 20 & 21 & 488 & 97.5 & 2.5 \\
20 & 15.5 & 15 & 609 & 99 & 1
\end{tabular}

In this phase diagram, the LLPS is metastable with respect to the solid-liquid phase separation. This is often observed in protein systems, because of short-range attraction between proteins. ${ }^{36}$ It is noteworthy that no primary nucleation was observed in the time frame of the experiments for the range of temperature and protein concentrations tested in this paper, 15$120 \mathrm{mg} / \mathrm{mL}$ and $15-26{ }^{\circ} \mathrm{C}$, respectively, while the solutions were supersaturated with respect to the solid phase. As a result, LLPS (the metastable phase) occurs prior to and impedes solid (the stable phase) primary nucleation, in agreement with the Oswald rule of stages. Finally, the protein concentration in the solid phase is about $640 \mathrm{mg} / \mathrm{mL}$ for the monoclinic form of BPTI (PDB entry 1BHC), the solidus line in Figure $2 \mathrm{~b}$.

2.2. Scattering Studies of BPTI Supersaturated Solutions. In a previous SAXS study, the BPTI LLPS was studied ${ }^{37}$ by temperature quench below the spinodal temperature. In the case of spinodal decomposition, the solution rapidly separated into two phases, and large droplets appeared and fell rapidly in the solution; thus, a bulk continuous second phase was formed. ${ }^{38}$ In this work, we performed binodal decomposition by slowly decreasing the temperature at a rate of $5^{\circ} \mathrm{C} / \mathrm{h}$. We thus expected

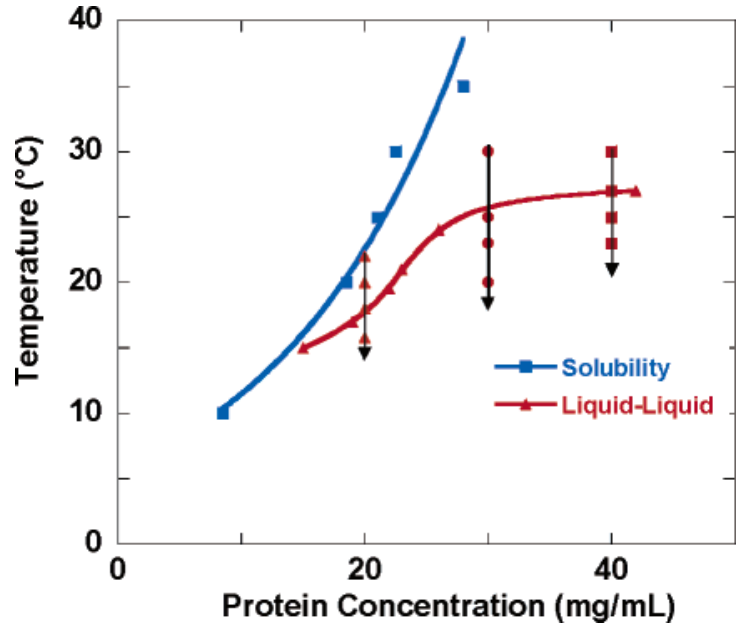

Figure 3. Conditions of the SAXS experiments in the partial phase diagram of $\mathrm{BPTI} / 350 \mathrm{mM} \mathrm{KSCN}$ at $\mathrm{pH}$ 4.9. Arrows represent the temperature shift at a rate of $5{ }^{\circ} \mathrm{C} / \mathrm{h}$.

to obtain a stable suspension of droplets during SAXS measurement. BPTI solutions at 20,30, and $40 \mathrm{mg} / \mathrm{mL}$ were prepared and separated into two batches. For the first batch, the scattering intensities were recorded at different temperatures above and below the $T_{\mathrm{L}-\mathrm{L}}$ boundary curve. The principle of the experiments is summarized in Figure 3. As clearly shown in this graph, all the protein solutions are supersaturated and even after the LLPS, the supernatant is still supersaturated. For the second batch, see the next section. 

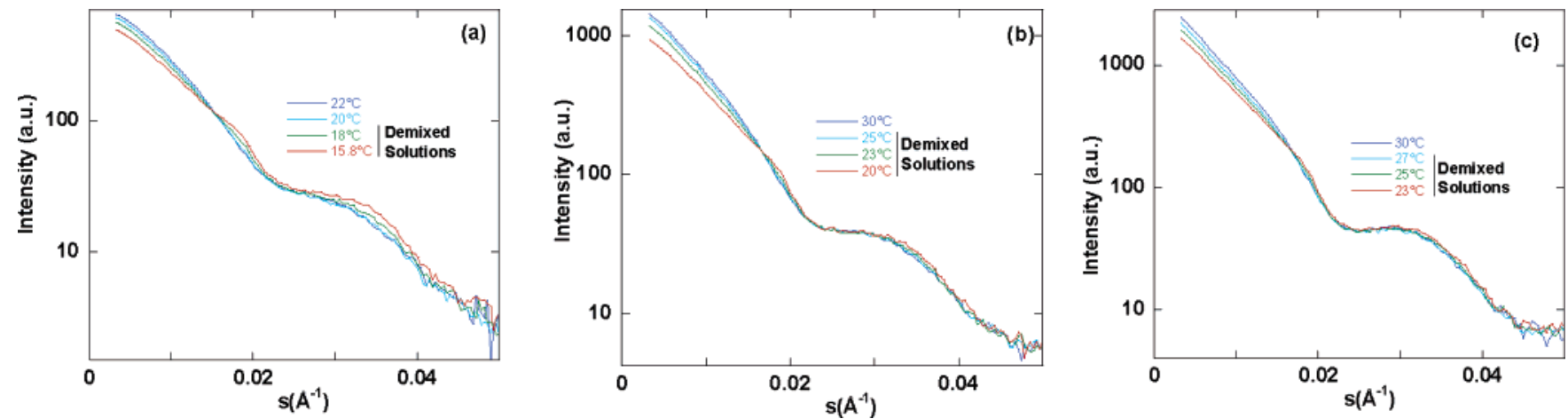

Figure 4. Scattering intensities of BPTI solutions at pH 4.9 and $350 \mathrm{mM} \mathrm{KSCN}$ at different temperatures for (a) $20 \mathrm{mg} / \mathrm{mL}$, (b) $30 \mathrm{mg} / \mathrm{mL}$, and (c) $40 \mathrm{mg} / \mathrm{mL}$.
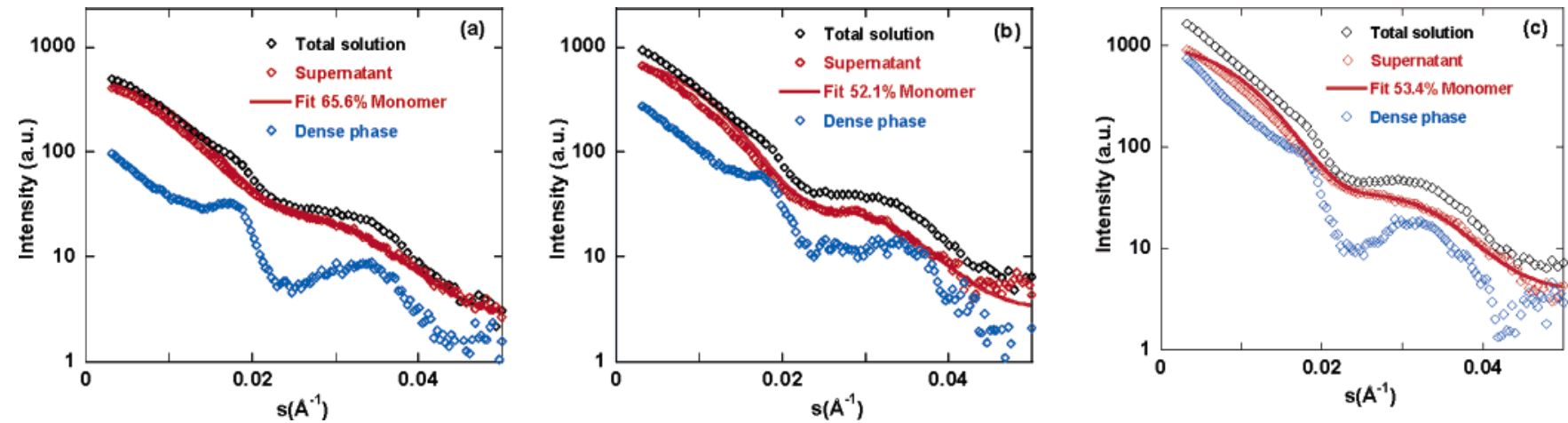

Figure 5. Scattering intensities of BPTI solutions at $\mathrm{pH} 4.9$ and $350 \mathrm{mM} \mathrm{KSCN}$ at (a) $15.5^{\circ} \mathrm{C}$ for $20 \mathrm{mg} / \mathrm{mL}$, (b) $20^{\circ} \mathrm{C} \mathrm{for} 30 \mathrm{mg} / \mathrm{mL}$, and (c) $23{ }^{\circ} \mathrm{C}$ for $40 \mathrm{mg} / \mathrm{mL}$. The solid lines represent the form factor fitting of the experimental points; the color code is as follows: black for the total solution, red for the supernatant, and blue for the dense phase obtained by subtracting the supernatant signal from the whole signal.

TABLE 2: Weight Fractions of Monomer and Calculated BPTI Concentrations from Curve Fits of SAXS Data after the LLPS in the Different Phases

\begin{tabular}{clccc}
\hline $\begin{array}{c}\text { protein } \\
\text { concn } \\
(\mathrm{mg} / \mathrm{mL})\end{array}$ & $\begin{array}{c}T \\
\left({ }^{\circ} \mathrm{C}\right)\end{array}$ & $\begin{array}{c}\text { supernatant } \\
(\mathrm{mg} / \mathrm{mL})\end{array}$ & $\begin{array}{c}\% \\
\text { monomer }\end{array}$ & $\begin{array}{c}\text { dense } \\
\text { phase } \\
(\mathrm{mg} / \mathrm{mL})\end{array}$ \\
\hline 40 & 23 & 25 & 53.4 & 489 \\
30 & 20 & 20 & 52.1 & 559 \\
20 & 15.5 & 16 & 65.6 & $846^{a}$
\end{tabular}

${ }^{a}$ This value is overestimated (the solidus line is estimated at 640 $\mathrm{mg} / \mathrm{mL}$ ).

2.2.1. Scattering Curves above and below the $T_{L-L}$ Boundary. Figure 4 shows the scattering intensities plotted as a function of temperature, above and below the $T_{\mathrm{L}-\mathrm{L}}$ boundary curve, for three different BPTI concentrations. We noticed no variation in scattering intensity at $s>0.02 \AA^{-1}$ when $T<T_{\mathrm{L}-\mathrm{L}}$, meaning that the droplet suspension is stable, i.e., no decantation occurs during these SAXS experiments. Thus, data presented in Figure 4 are representative of the total solution after the LLPS, namely both phases.

To thoroughly characterize the system, we performed complementary SAXS experiments on the low-concentration or supernatant phase after the LLPS occurred. These solutions were obtained by mechanical separation of the second batch at 15.5, 20 , and $23{ }^{\circ} \mathrm{C}$ for initial concentrations of 20,30 , and $40 \mathrm{mg} /$ $\mathrm{mL}$, respectively. By subtraction from the intensity of the total demixed solution, we obtained the intensity scattered by the high-concentration or dense phase (Figure 5). Moreover, the procedure described in section 2.3.2.1 makes it possible to determine the ratio of monomers to decamers and the protein concentration in the supernatant (for the dense phase see section 2.2.3). These results are summarized in Table 2. To discuss these results, we have, first, fitted the experimental scattering intensi-

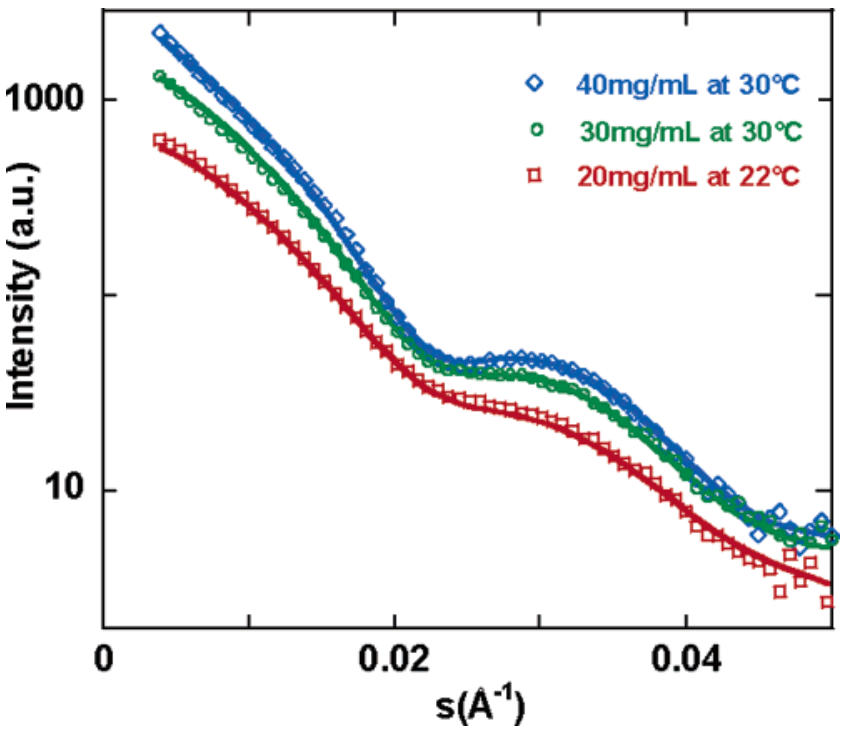

Figure 6. Experimental (open points) and theoretical (lines) scattering intensities of BPTI solutions at pH 4.9 and $350 \mathrm{mM} \mathrm{KSCN}$ at (a) 22 ${ }^{\circ} \mathrm{C}$ for $20 \mathrm{mg} / \mathrm{mL}$, (b) $30{ }^{\circ} \mathrm{C}$ for $30 \mathrm{mg} / \mathrm{mL}$, and (c) $30{ }^{\circ} \mathrm{C}$ for $40 \mathrm{mg} /$ $\mathrm{mL}$. Theoretical intensities calculated from the two-components model.

ties measured above the $T_{\mathrm{L}-\mathrm{L}}$ boundary, using eq 4 , therefore obtaining the theoretical structure factors.

2.2.2. Structure Factors above the $T_{L-L}$ Boundary. The twocomponent model was used to fit the experimental curves for 20, 30, and $40 \mathrm{mg} / \mathrm{mL}$ obtained at 22,30 , and $30{ }^{\circ} \mathrm{C}$, respectively (Figure 6). Indeed, at these temperatures, the solutions were stable with respect to the LLPS although supersaturated. As written in eq 4, four terms must be determined to account for the scattering intensity: three structure factors and the monomer-to-decamer ratio, which gives the 
TABLE 3: Weight Fractions of Monomer Used in the Two-Component Model (Figure 6)

\begin{tabular}{ccc}
\hline $\begin{array}{c}\text { protein } \\
\text { concn } \\
(\mathrm{mg} / \mathrm{mL})\end{array}$ & $\begin{array}{c}T \\
\%\end{array}$ \\
\hline 40 & $\left({ }^{\circ} \mathrm{C}\right)$ & monomer \\
30 & 30 & 35.1 \\
20 & 30 & 44.7 \\
& 22 & 67
\end{tabular}

TABLE 4: van der Waals Parameters Used for the Two-Component Model (Figure 6)

\begin{tabular}{ccc}
\hline & $d^{a}(\AA)$ & $J^{b}(\mathrm{kT})$ \\
\hline monomer-monomer & 1.5 & 3.1 \\
monomer-decamer & 2 & 3.3 \\
decamer-decamer & 2.5 & 4.5 \\
${ }^{a}$ Range of the attractive potential. ${ }^{b}$ Depth of the attractive potential.
\end{tabular}

monomer and decamer concentrations. For this reason, we used a two-step method. First, we determined the monomer-todecamer ratio as explained in section 2.3.2.1; namely, we ignored the influence of the structure factor in the $s$-range $0.02-$ $0.035 \AA^{-1}$ (Table 3). Second, we determined the monomermonomer, monomer-decamer, and decamer-decamer pair interaction potentials. The best-fit parameters are presented in Table 4, with a hard-core diameter of 26 and $50 \AA$ and a charge of +5 and +8 for the monomer and the decamer, respectively, for an ionic strength of $385 \mathrm{mM}$. Surprisingly, the decamer charge is very low, +8 , which is due to the presence of thiocyanate ions in the central channel of the decamer, reducing the high internal positive charge density. ${ }^{34,39}$ The results presented in Table 4 clearly indicate that decamer-decamer potential is extremely attractive in comparison with monomermonomer and monomer-decamer potentials. Thus, the driving force for the liquid-solid phase separation is the attraction between decamers.

2.2.3. Scattering Curves of the Dense Phase below the $T_{L-L}$ Boundary. In the present study, it is very difficult to elucidate the composition of the dense phase. There are two principal reasons for this: (1) the dense-phase scattering intensity is not directly measured, meaning the signal is noisy, and (2) the difficult problem in SAXS data treatment (the experimental curve is the product of the particle form factor by the solution structure factor) is complicated by the binary mixture of monomers and decamers. As written in eq 4, four terms must be determined to account for the scattering intensity: three structure factors and the monomer-to-decamer ratio, which gives the monomer and decamer concentrations, meaning that there is not a single solution.

Figure 7 shows the scattering intensities of the dense phases of Figure 5 plotted on the same graph, and curves are normalized by the concentrations of Table 2 . The scattering curves behave as already observed in the case of LLPS of urate oxidase/PEG mixtures: ${ }^{27}$ the scattering intensity decreases for $s<0.0175 \AA^{-1}$ and a peak appears at $s \approx 0.0175 \AA^{-1}$.

First, we determined the monomer-to-decamer ratio as explained in section 2.3.2.1; namely, we ignored the influence of the structure factor in the $s$-range $0.02-0.035 \AA^{-1}$. In that case, a dense phase composed of decamers alone is apparently the best fit for the dense-phase scattering curves, in agreement with data of Table 3 and previous experiments of Hamiaux, ${ }^{40}$ indicating that when BPTI concentration is increased, the percent decamer increases, in that case up to $100 \%$. Moreover, the BPTI concentrations calculated from the SAXS data (Table 2) are in good agreement with the direct titration experiments presented in Table 1.

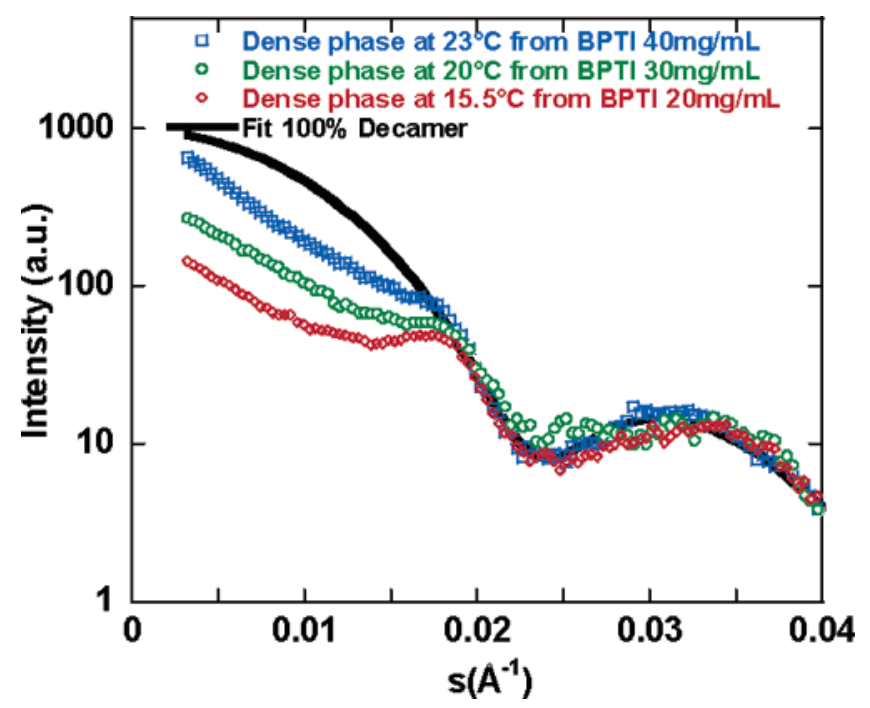

Figure 7. Experimental scattering intensities of the BPTI dense phase at $\mathrm{pH} 4.9$ and $350 \mathrm{mM} \mathrm{KSCN}$ at $15.5,20$, and $23{ }^{\circ} \mathrm{C}$ for an initial concentration before LLPS of 20,30 , and $40 \mathrm{mg} / \mathrm{mL}$ respectively, corresponding to dense phase concentrations of 846,559 , and $489 \mathrm{mg} /$ $\mathrm{mL}$, respectively.

Second, the protein concentration in the dense phase is very high and approaches the protein concentration in the crystalline phase, about $640 \mathrm{mg} / \mathrm{mL}$ for the monoclinic form of BPTI, which corresponds to an interparticle distance of $53 \AA$. In the dense phase, proteins are actually in contact and their hard sphere repulsive core explains why we obtain a structure factor below 1 at $s<0.0175 \AA^{-1}$. Moreover, at very low scattering vectors, there is an increase in the experimental scattering curve due to the droplet interface, as previously suggested by Vivares and Bonneté. ${ }^{27}$

2.3. Implication for BPTI Crystallization. 2.3.1. Decameric Crystallization of BPTI at Low $p H$. In previous work, ${ }^{33,41}$ we have shown that, for the three new BPTI polymorphs grown at $\mathrm{pH} 4.9$, the growth unit was the decamer. Moreover, crystals were grown from polydisperse solutions of monomers and decamers with the proportion of monomers ranging from $85 \%$ to $34 \%$. Concerning the polymorphism of BPTI as a function of $\mathrm{pH}$, Gottschalk et al. ${ }^{39}$ have asked an interesting question: "Why, then, are monomeric crystals obtained at high $\mathrm{pH}$ and decameric crystals at low $\mathrm{pH}$ ?" The results presented in Table 4 answer the question for the low-pH crystals, since decamerdecamer attraction is stronger than monomer-monomer attraction. Thus, the driving force for crystallization is the attraction between decamers. Crystallization at high $\mathrm{pH}$ values will be discussed in another paper in preparation.

2.3.2. BPTI Nucleation and LLPS. Our results on the nucleation behavior of BPTI decameric crystals relative to the LLPS are in agreement with those reported for other proteins (see the review by Vekilov ${ }^{42}$ ); namely, nucleation is enhanced above $T_{\mathrm{L}-\mathrm{L}}$ and the nucleation is suppressed within the BPTI dense phase. Suppression of nucleation of lysozyme crystals within the dense phase has been attributed to the high viscosity of the lysozyme dense phase, which considerably diminishes the material diffusion. ${ }^{43}$ The SAXS results for the BPTI dense phase showed repulsive protein-protein interactions. Proteins are not aggregated, but due to the high protein concentration, they are in a gel-like state in which the diffusivity is zero, as in the solid state. In the cases of lysozyme and BPTI, the metastable liquid phase impedes the nucleation of the solid phase, which was also observed for some organic molecules. ${ }^{44,45}$ Note that recently, in an extremely interesting paper from 
Vivarès et al. ${ }^{46}$ on the crystallization of glucose isomerase in the presence of a metastable LLPS observed by confocal scanning fluorescence microscopy, it has been shown that nucleation and crystal growth mainly occurred inside the dense phase.

Finally, we propose the following practical rule for crystallization: when we observe a demixion, it is bound to be metastable with respect to crystallization and therefore the best crystallization temperature is $T$, with $T_{\mathrm{e}}>T \geq T_{\mathrm{L}-\mathrm{L}}$, where $T_{\mathrm{e}}$ is the crystal-liquid equilibrium temperature.

Note that, here, we propose a practical rule for experimentalist for whom $C$ and $T_{\mathrm{L}-\mathrm{L}}$ values are experimentally accessible, for their biological system, during crystallization experiments. For instance, the opacification of solutions during crystallization experiments can be observed; this is not the case for the critical point or the spinodal temperature, as suggested by Palma et al. ${ }^{47}$ Clearly, the critical point and temperature or spinodale temperature are important values in the phase diagram, but their influence on crystallization is not yet clear. For instance, Galkin and Vekilov ${ }^{26}$ showed the influence of $T_{\mathrm{L}-\mathrm{L}}$ on the nucleation rate, confirming that the practical parameter is $T_{\mathrm{L}-\mathrm{L}}$.

2.4. Biological Relevance. The present study confirms the BPTI self-association into decamers at $\mathrm{pH} 4.5$ and shows the importance of the attraction between decamers for BPTI phase separations. A better knowledge of protein phase separations has potential applications in biophysics. For instance, liquidliquid phase separation is routinely encountered in membrane protein crystallization studies, but it is not well characterized or understood. Finally, the protein studied here is a new model system for the phase separation studies, in complement to lysozyme and crystallin proteins studied by numerous groups.

But the functional role for decamer is still not well understood. Gottschalk et al. ${ }^{39}$ have proposed a functional role for BPTI decamer in the secretory granules of mast cells, whereas Hamiaux et al. ${ }^{33}$ thought it is highly improbable that BPTI decamerization would occur under physiological conditions.

\section{Conclusions}

This paper provides an investigation of the phase diagram of BPTI/350 mM KSCN at $\mathrm{pH} 4.9$ by direct observation and numerical simulations. We report optical microscopy and light and X-ray scattering experiments coupled to theoretical data analysis using numerical tools developed by Belloni et al. We thoroughly determine the phase diagram, namely, liquidus, solidus, and liquid-liquid equilibrium curves. We observe two polymorphs by video microscopy and we measure their solubility. We find that the solubility of the chloride-like hexagonal polymorph is reverse with temperature and the monoclinic is direct, with solubility curves crossing at $12{ }^{\circ} \mathrm{C}$. In this phase diagram, the LLPS is metastable with respect to the solid-liquid phase separation.

We characterize the BPTI solutions below and above the $T_{\mathrm{L}-\mathrm{L}}$ boundary curves by SAXS and numerical simulation of the form and structure factors. Above the $T_{\mathrm{L}-\mathrm{L}}$ boundary, solutions are composed of a mixture of BPTI monomers and decamers, with stronger attractive interactions between decamers than between monomers. Below the $T_{\mathrm{L}-\mathrm{L}}$ boundary, the dense phase is highly concentrated in proteins and composed of BPTI decamers alone. Thus, the driving force for liquid-liquid or liquid-solid phase separation is the attraction between decamers at low $\mathrm{pH}$.

Moreover, the structure factors of the dense phases are characteristic of a repulsive dense phase because of a hard sphere repulsive core, meaning that in the dense phase proteins are actually in contact (interparticle distance of $53 \AA$ ). Finally, we have shown, in agreement with the Oswald rule of stages, that LLPS occurs prior to and impedes solid nucleation. Low diffusivity and repulsive interactions of BPTI decamers in the dense phase explain this result.

\section{Materials and Methods}

4.1. Materials. BPTI, commonly used as an anticoagulant to reduce blood loss during cardiac surgery, was supplied as a lyophilized powder by Bayer and used as received without further purification. The purity was checked by molecular sieving HPLC. ${ }^{35}$ The necessary quantities of BPTI (6511 Da, $\mathrm{p} I=10.5)$ and $\mathrm{KSCN}$ were dissolved in pure water (ELGA UHQ reverse osmosis system) to obtain stock solutions for phase-separation determination. The different solutions were buffered with acetic acid to $80 \mathrm{mM}$, adjusted to $\mathrm{pH} 4.5$ with $\mathrm{NaOH}(1 \mathrm{M})$, and filtered through $0.22 \mu \mathrm{m}$ Millipore filters. After dissolution of BPTI, the $\mathrm{pH}$ was 4.9. The BPTI concentration $(C)$ was measured by optical density measurements using an extinction coefficient of $0.786 \mathrm{~cm}^{-1} \mathrm{~mL} \mathrm{mg}^{-1}$ at $280 \mathrm{~nm} .{ }^{18}$ Throughout this study, the salt concentration was fixed at 350 $\mathrm{mM} \mathrm{KSCN}$ and the $\mathrm{pH}$ at 4.9 .

4.2. $(\boldsymbol{C}, \boldsymbol{T})$ Phase Diagram. BPTI solubilities were determined at different temperatures by seeding supersaturated solutions with small BPTI crystallites and by following the decrease of protein concentration by UV spectrophotometry until it remained unchanged for at least 2 weeks.

Three methods were used to determine the BPTI liquidliquid coexistence curve as a function of temperature, hereafter also called the $T_{\mathrm{L}-\mathrm{L}}$ boundary. In the first method, variation in static light scattering intensity at $90^{\circ}$ of BPTI solutions of known concentrations were recorded as a function of temperature. ${ }^{37,48}$ The light scattering experimental setup (SEM 633, SematechFrance) has previously been described elsewhere. ${ }^{49}$ The appearance of liquid droplets when temperature was decreased induced a jump in the scattering intensity, designated as $T_{\mathrm{L}-\mathrm{L}}$. After the L-L phase demixion had occurred, when temperature was increased above $T_{\mathrm{L}-\mathrm{L}}$, the cloudiness responsible for the strong signal peak readily disappeared. In the second method, several couples $\left(C, T_{\mathrm{L}-\mathrm{L}}\right)$ were verified by optical microscope. BPTI solutions were placed in a $100-\mu \mathrm{L}$ quiescent glass vessel inserted in a thermostated cell under an optical microscope (Nikon Diaphot) and the droplet temperature equilibrium was measured. ${ }^{45}$ Last, BPTI solutions at initial temperatures well above the coexistence curve were rapidly quenched to a temperature below their cloud points. Phase separation rapidly occurred and the solutions underwent a macroscopic gravitydriven separation into two coexisting phases. In addition, the solutions $(500 \mu \mathrm{L})$ were centrifuged for $1 \mathrm{~h}$ at $10000 \mathrm{rpm}$ in a thermostated Eppendorf 5804R centrifuge. The two phases were separated by a sharp meniscus. The BPTI concentrations, volumes, and weights of the two phases were measured.

4.3. Small-Angle X-ray Scattering. 4.3.1. SAXS Experiments. $\mathrm{X}$-ray scattering intensities were recorded on the SAXS instrument D24 using the synchrotron radiation emitted by the DCI storage ring at the Laboratory for Synchrotron Radiation, L.U.R.E. ${ }^{50-52}$ The sample-detector distance was $1139 \mathrm{~mm}$ and the X-rays wavelength was $1.488 \AA$. The intensity curves were scaled to the transmitted intensity, and the background (i.e. saltbuffer signal) was subtracted from the scattering curve of BPTIsalt-buffer mixtures.

With solutions of monodisperse spherical particles in interaction, the total normalized intensity $I(c, s)$, scattered at a scattering 
angle $2 \theta$, can be expressed as a function of the modulus of the scattering vector $s\left(s=2 \lambda^{-1} \sin \theta\right)$ and of the particle concentration $c$ by

$$
I(c, s)=I(0, s) S(c, s)
$$

$I(0, s)$, the intensity scattered by one particle, is the Fourier transform of the spherically averaged autocorrelation function of the electron density contrast associated with the particle, namely the particle form factor. ${ }^{53}$ Note that for a polydisperse solution of two protein oligomers, the total form factor is the sum of the form factors of the two oligomers, weighted by their respective quantities.

$S(c, s)$, namely the solution structure factor, reflects interactive effects due to attractive or repulsive interactions between particles. ${ }^{54}$ To extract the experimental structure factor, the form factor is needed. The structure factor, $S(c, s)$, is the Fourier transform of the spherically averaged autocorrelation function $g(r)$ of the particle distribution or pair-distribution function

$$
S(c, s)=1+\rho \int 4 \pi r^{2}(g(r)-1) \frac{\sin 2 \pi r s}{2 \pi r s} \mathrm{~d} r
$$

where $\rho=N_{\mathrm{a}} / M$ is the particle number density, $c$ is the particle concentration $\left(\mathrm{g} / \mathrm{cm}^{3}\right)$, and $r$ is the interparticle distance. The structure factor at the $s$-origin, $S(c, 0)$, is proportional to compressibility. With repulsive interactions, the particles are evenly distributed and $S(c, 0)$ is lower than 1 , whereas with attractive interactions, fluctuations in the particle distribution are observed, leading to a $S(c, 0)$ value larger than 1 .

4.3.2. Simulation Procedures. 4.3.2.1. Form Factors. In a binary mixture of BPTI monomers and decamers, the experimental scattering curves were systematically fitted by a linear combination of monomers and decamers as described by Hamiaux. ${ }^{33}$ Calculated form factors for BPTI monomer and decamer were obtained using the CRYSOL program ${ }^{55}$ from a set of crystallographic coordinates (PDB entry $\left.1 \mathrm{BHC}^{34}\right)$. At very low scattering vectors, $\left(s<0.02 \AA^{-1}\right)$, interparticle interactions may perturb the scattering intensity and affect the form factor. To minimize this effect, we decided to only consider the scattering vector range from 0.02 to $0.035 \AA^{-1}$. The fitting curve procedure was performed using an IDL program (Research systems). For every linear combination, the fit residual $\chi^{2}$ was calculated, according to the following equation

$$
\chi^{2}=\frac{1}{N} \sum_{j=1}^{N}\left(\frac{y-y_{j}}{\sigma_{j}}\right)^{2}
$$

where $N$ is the total number of experimental points, $y$ is the experimental value, $y_{j}$ the corresponding simulated value, and $\sigma_{j}$ the experimental error. The best fit corresponds to the smallest $\chi^{2}$, and in every case, the plot of residuals, namely, the normalized difference between the experimental curve and the fit, was generated to monitor visually the accuracy of the fit.

Two parameters were taken into account for the fitting procedure: the protein concentration (the sum of the mass coefficients attributed to monomer and decamer form factors) and the percentage of decamers.

4.3.2.2. Structure Factors. In this paper, we focus on the structure factors above and below the $T_{\mathrm{L}-\mathrm{L}}$ boundary curve. In the case of monodisperse BPTI solutions, structure factors were calculated from the Fourier transform and integrals of the pair distribution function $g(r)$, using the one-component model. ${ }^{56}$ In this model, the monodisperse particles interact via a screened Coulombic potential, the counterions and salt ions acting only implicitly through the screening constant. In a binary mixture of BPTI monomers and decamers, partial structure factors and pair distribution function $g_{i, j}(r)$ must be calculated using a twocomponent model. ${ }^{57}$ In the latter, the monomers, the decamers, and the ions, which interact through the Coulombic potentials, are explicitly taken into account. The total scattered intensity of the solution can therefore be written as

$$
\begin{aligned}
I(c, s)= & C_{\mathrm{m}} I_{\mathrm{m}}(0, s) S_{\mathrm{mm}}(c, s)+ \\
& 2 \sqrt{C_{\mathrm{m}} C_{\mathrm{d}}} \sqrt{I_{\mathrm{m}}(0, s) I_{\mathrm{d}}(s)} S_{\mathrm{md}}(c, s)+C_{\mathrm{d}} I_{\mathrm{d}}(0, s) S_{\mathrm{dd}}(c, s)
\end{aligned}
$$

where the subscript $\mathrm{m}$ and $\mathrm{d}$ refer to the BPTI monomers and decamers and $C_{i}$ is the particle concentration. The calculation of $g(r)$ and $g_{i, j}(r)$ was based on the Ornstein-Zernike equation and the hypernetted chain integral equation and used an iterative method developed by Belloni. ${ }^{56,58}$ The DLVO potential was used as previously described. ${ }^{59}$

Acknowledgment. We thank Bayer A.G. (Wuppertal, Germany) for providing us with BPTI. We thank Drs. L. Belloni (CEA Saclay) and D. Vivares for fruitful and critical discussions and M. Sweetko for english revision.

\section{References and Notes} 815.

(1) Anderson, V. J.; Lekkerkerker, H. N. W. Nature 2002, 416, 811-

(2) Poon, W.; Pusey, P.; Lekkerkerker, H. Phys. World 1996, 27-32. (3) Blundell, T. L.; Jhoti, H.; Abell, C. Nat. Rev. Drug Discovery 2002, $1,45-54$.

(4) Ishimoto, C.; Tanaka, T. Phys. Rev. Lett. 1977, 39, 474-477.

(5) Hofrichter, J.; Ross, P. D.; Eaton, W. A. Proc. Natl. Acad. Sci. U.S.A. 1974, 71, 4864-4868.

(6) Brange J. Galenics of Insulin; Springer-Verlag: Berlin, 1987.

(7) Leavis, P. C.; Rothstein, F. Arch. Biochem. Biophys. 1974, 161, $671-682$.

(8) Berland, C.; Thurston, G.; Kondo, M.; Broide, M.; Pande, J.; Ogun, O.; Benedek, G. Proc. Natl. Acad. Sci. U.S.A. 1992, 89, 1214-1218.

(9) Broide, M. L.; Tominc, T. M.; Saxowsky, M. D. Phys. Rev. E 1996, $53,6325-6335$.

(10) Ries-Kautt, M. M.; Ducruix, A. F. J. Biol. Chem. 1989, 264, 745748.

(11) Ataka, M.; Asai, M. J. Cryst. Growth 1988, 90, 86-93.

(12) Howard, S. B.; Twigg, P. J.; Baird, J. K.; Meehan, E. J. J. Cryst. Growth 1988, 90, 94-104.

(13) Mikol, V.; Giege, R. J. Cryst. Growth 1989, 97, 324-332.

(14) Demattei, R. C.; Feigelson, R. S. J. Cryst. Growth 1991, 110, 3440.

(15) Boistelle, R.; Astier, J. P.; Marchis-Mouren, G.; Desseaux, V.; Haser, R. J. Cryst. Growth 1992, 123, 109-120.

(16) Veesler, S.; Lafont, S.; Marcq, S.; Astier, J. P.; Boistelle, R. J. Cryst. Growth 1996, 168, 124-129.

(17) Carbonnaux, C.; Ries-Kautt, M.; Ducruix, A. Protein Sci. 1995, 4, $2123-2128$.

(18) Lafont, S.; Veesler, S.; Astier, J. P.; Boistelle, R. J. Cryst. Growth 1994, 143, 249-255.

(19) Petsev, D. N.; Thomas, B. R.; Yau, S. T.; Tsekova, D.; Nanev, C.; Wilson, W.; Vekilov, P. G. J. Cryst. Growth 2001, 232, 21-29.

(20) Budayova, M.; Astier, J. P.; Veesler, S.; Czjzek, M.; Belaich, A.; Boistelle, R. J. Cryst. Growth 1999, 196, 297-304.

(21) Gaucher, J. F.; Riès-Kautt, M.; Reiss-Husson, F.; Ducruix, A. FEBS Lett. 1997, 401, 113-116.

(22) Stradner, A.; Sedgwick, H.; Cardinaux, F.; Poon, W., C K. Egelhaaf, S., U,; Schurtenberger, P. Nature 2004, 432, 492-495.

(23) Frenkel, D. Physica A 1999, 263, 26-38.

(24) Muschol, M.; Rosenberger, F. J. Chem. Phys. 1997, 107, 19531961.

(25) Haas, C.; Drenth, J. J. Cryst. Growth 1999, 196, 388-394.

(26) Galkin, O.; Vekilov, P. G. Proc. Natl. Acad. Sci. U.S.A., 2000, 97 , $6277-6281$.

(27) Vivares, D.; Bonnete, F. J. Phys. Chem. B 2004, 108, 6498-6507.

(28) Finet, S.; Bonnete, F.; Frouin, J.; Provost, K.; Tardieu, A. Eur. Biophys. J. 1998, 27, 263-271.

(29) Budayova-Spano, M.; Bonnete, F.; Astier, J. P.; Veesler, S. J. Cryst. Growth 2002, 235, 547-554.

(30) Yau, S. T.; Vekilov, P. G. Narture 2000, 406, 494-497.

(31) Durbin, S. D.; Carlson, W. E. J. Cryst. Growth 1992, 122, 71-79. 
(32) Astier, J. P.; Bokern, D.; Lapena, L.; Veesler, S. J. Cryst. Growth 2001, 226, 294-302.

(33) Hamiaux, C.; Perez, J.; Prangé, T.; Veesler, S.; Ries-Kautt, M.; Vachette, P. J. Mol. Biol. 2000, 297, 697-712.

(34) Hamiaux, C.; Prangé, T.; Ries-Kautt, M.; Ducruix, A.; Lafont, S.; Astier, J. P.; Veesler, S. Acta Crystallogr. 1999, D55, 103-113.

(35) Veesler, S.; Ferté, N.; Costes, M. S.; Czjzek, M.; Astier, J. P. Cryst. Growth Des. 2004, 4, 1137-1141.

(36) Wolde, P. R.; Frenkel, D. Science 1997, 277, 1975-1978.

(37) Grouazel, S.; Perez, J.; Astier, J.-P.; Bonneté, F.; Veesler, S. Acta Crystallogr. 2002, D58, 1560-1563.

(38) Vitale, S. A.; Katz, J. L. Langmuir 2003, 19, 4105-4110.

(39) Gottschalk, M.; Venu, K.; Halle, B. Biophys. J. 2003, 84, $3941-$ 3958.

(40) Hamiaux, C. Cristallogenèse du BPTI à pH acide: étude des relations entre l'état d'association des molécules en solution et à l'état cristallin par diffusion et diffraction des RX. Université Paris XI, 2000.

(41) Bonneté, F.; Ferté, N.; Astier, J. P.; Veesler, S. J. Phys. IV 2004 118, 3-13.

(42) Vekilov, P. G. Cryst. Growth Des. 2004, 671-685.

(43) Evans, R. M. L.; Poon, W. C. K.; Cates, M. E. Europhys. Lett. 1997, 38, 595-600

(44) Lafferrere, L.; Hoff, C.; Veesler, S. Cryst. Growth Des. 2004, 4, $1175-1180$

(45) Veesler, S.; Lafferrere, L.; Garcia, E.; Hoff, C. Org. Proc. Res. Dev. 2003, 7, 983-989.
(46) Vivarès, D.; Kalera, E. W.; Lenhoff, A. M. Acta Crystallogr. Sect D 2005, 61, 819-825.

(47) Pullara F.; Emanuele A.; Palma-Vittorelli M. B.; Palma M. U. J. Cryst. Growth 2005, 274, 536-544.

(48) Lafferrere, L.; Hoff, C.; Veesler, S. J. Cryst. Growth 2004, 269 $550-557$

(49) Veesler, S.; Marcq, S.; Lafont, S.; Astier, J. P.; Boistelle, R. Acta Crystallogr. 1993, D50, 355.

(50) Boulin, C.; Kempf, R.; Koch, M. H. J.; Mclaughlin, S. M. Nucl. Instrum. Methods Phys. Res. Sect. A 1986, 249, 399-407.

(51) Dubuisson, J.-M.; Decamps, T.; Vachette, P. J. Appl. Crystallogr. 1997, 30, 49-54.

(52) Depautex, C.; Desvignes, C.; Feder, P.; Lemonnier, M.; Bosshard, R.; Leboucher, P.; Dageaux, D.; Benoit, J. P.; Vachette, P. "LURE: rapport d'activité pour la période aout 1985-1987', 1987.

(53) Luzzati, V.; Tardieu, S. A. Annu. Rev. Biophys. Bioeng. 1980, 9, $1-29$.

(54) Tardieu, A. Cours Hercules 1994, III, 145-160.

(55) Svergun, D.; Barberato, C.; Koch, M. H. J. J. Appl. Crystallogr. 1995, 28, 768-773.

(56) Belloni, L. Chem. Phys. 1985, 99, 43-54.

(57) Vivares, D.; Belloni, L.; Tardieu, A.; Bonnete, F. Eur. Phys. J. E 2002, 9, 15-25

(58) Belloni, L. J. Chem. Phys. 1988, 88, 5143-5148.

(59) Tardieu, A.; Le Verge, A.; Malfois, M.; Bonneté, F.; Finet, S.; RiesKautt, M.; Belloni, L. J. Cryst. Growth 1999, 196, 193-203. 